\title{
Nacionalismo e Literatura em Portugal: Dois dos equívocos da caligrafia única (1932-1945)
}

\author{
Nationalism and Literature in Portugal: \\ Two of the misjudgments of the mainstream (1932-1945)
}

Paulo Archer de Carvalho

Doutor em Letras

Investigador do CEIS20 da Universidade de Coimbra pauloarcher33@yahoo.com.br

Resumo: O Estado Novo não conseguiu criar um cânone de "nacionalismo literário", quer quando projetou uma "política do espírito", quer quando tentou nacionalizar e converter em ortodoxia a mitopoética heterodoxa de Pessoa em Mensagem. Sob o ponto de vista hermenêutico, o nacionalismo representou, para Pessoa, uma outra face para apreender o ecumenismo profético que a sua escrita arrasta e o universalismo, situado e descentrado, que a sua Poesia exige.

Ao invés, o regime paradoxalmente adoptou a Mensagem como cânone, em busca de raízes mitológicas para a sua própria afirmação política e de pré-textos fundamentadores da sua sobrevivência ideológica.

Palavras-chave: Nacionalismo literário, política do espírito, Fernando Pessoa, Mensagem.
Abstract: Estado Novo not manage to create a canon of "literary nationalism", either when it drew a "Política do Espírito", or when it tried to nationalize and turn into orthodoxy a heterodoxic "mitopoiética" of Fernando Pessoa in Mensagem. From the hermeneutic point of view, nationalism represented for Pessoa a different face to apprehend the prophetic ecumenism that his writing draws, and the universalism, situated and decentered, that his Poetry demands.

Instead, Estado Novo paradoxically adopted Mensagem as a canon in search of mythological roots for its own political assertion and pre-texts underlying its ideological survival.

Keywords: Literary nationalism, Política do espírito, Fernando Pessoa, Mensagem. 
Entre o alvor da década de 30 do século XX e o final da II Guerra Mundial, no fundo da cratera e dos incêndios do tempo, provavelmente o mais difícil será determinar, com razoabilidade crítica e rigor hermenêutico, o que se entende, em Portugal, por "literatura" afecta ao Estado Novo.

O II modernismo seria em grande parte estranho à épica (e à retórica) ressurreição nacional, como o evidenciam a escrita e os escritores, os artistas, numa palavra, os intelectuais agrupados na presença (1927-1940) e à volta dela; e estranho seria o neorealismo, em 1937, 1938, mirando fixo no Sol nascente a denúncia da miséria social e a promessa adâmica da Terra redentora; e o I modernismo estilhaçara-se já pela passagem tão intensa quanto meteórica de Fernando Pessoa, meteoro que após a vita brevis de Mário de Sá-Carneiro e a par da autolatria escrita de Almada Negreiros, em vinte anos tudo secará em volta, como cinzas vivas do vulcão extinto, dilacerando o $E u$ por ele mesmo ser autoconstitutivo de múltiplas abstracções, os possíveis de si. Dir-se-á que aparentemente não deixaria mais espaço a outros.

Restava, é hoje mais clara esta leitura, o que não morrera ainda do nacionalismo literário e se arrasta, em condição terminal, desde o neogarrettismo finissecular; e nele a invocação tardo-romântica, por muitos prolongada até à agonia salazarista, da felicidade pela agricultura e a inculcação do gosto horaciano pela inflação poética dos valores da terra, correlata da deflacionada vida artificial que a cidade grande gera e vive, numa antropologia sem Deus e numa sociologia de operários pobres onde o confessionalismo literário não entra. Mais tradicionalista do que «revolucionário», mais retaguarda do que vanguarda, também no campo das letras, o que o Estado Novo promoveu, impeliu, fez ler (nos concursos oficiais, nas escolas oficiais, na imprensa vigiada, nas rádios oficiosas) como literatura, não era mais do que o lugar ordeiro (tida como o espelho social de uma ordem cósmica e providencial) onde os mortos ali ressuscitavam: o primado da ancestral autoridade nada tinha do incendiário fascista que blasfema; não há Célines, ou Ezra Pound's a medrarem nos muros alvos das aldeias doiradas de Salazar e dos literatos oficiais que, mal, o escoltam.

Excluindo porventura António Ferro, ou Almada Negreiros (assaz surpreendente na novela Nome de Guerra), há antes uma plêiade de escritores da segunda divisão que não consegue ocupar a praça pública, à luz da qual são os grandes romancistas, oposicionistas, legíveis, mesmo se combatidos ou talvez por isso, num país que produz mais analfabetos do que simples graduados liceais. E à outra-escala, consensual então, que se jogava na manutenção e exploração do longínquo império colonial, raras vozes ou 
máquinas de escrever de literatos se registam na contestação à mais velha presença europeia dos bocados de uma nação, expandida ou migrada pelas partidas (por vezes quasi ignoradas) do mundo.

Texto sinóptico de uma das linhas de investigação que o autor há muito prossegue (CARVALHO, 1994; 1996; 2003; 2011; 2011-2012), apresentam-se esquematicamente algumas das conclusões que serviram de guião para a homónima comunicação no $45 .^{\circ}$ Annual Meeting da ASPHS, Association for Spanish and Portuguese Historical Studies,Modena (Itália, 2014).

\section{Equívoco anteprimeiro}

No período que medeia a ascensão e consolidação do Estado Novo (1932), para cuja feição institucional e matriz ideológica a repressão cívica correlata da mitificação salvífica de Salazar é cada vez mais determinante desde 1928-1930 - e o final da II Grande guerra, conflito distante mas que cruzara a geografia Ibérica onde, apesar da morte aparente dos nacionalismos bélicos europeus, as duas ditaduras são ratificadas internacionalmente, é a Era da gestação e queda do primeiro grande equívoco doutrinário do Estado Novo. Ideólogos e vigilantes directores dos serviços do regime verificam não ser possível traçar rotas definitivas para uma literatura nacionalista, pois não é possível «nacionalizar» a literatura e convertê-la em mero bureau de estado ou organismo corporativo. O modelo de uma caligrafia única, da aspiração a uma voz, que a didactologia política impunha, encontrou nas práticas literárias não só as maiores resistências como as maiores incompreensões.

O reino polifónico da literatura não é um edifício estático ao qual se imponham previamente regras de espaço, construção ou desenho; nem código penal, pois a ductilidade das palavras foge à norma temporalizadora que as tenta capturar. Impossibilitado de controlar o movimento editorial, a gestão privada dos livros e casas livreiras ou, até, face ao fracasso do anunciado programa da agitprop, conduzido a partir de 1933 na SPN (Sociedade da Propaganda Nacional) por António Ferro, no que toca à criação e controlo de colecções de divulgação "popular" (outro paradoxo: o povo, mais de $60 \%$ dos maiores de 7 anos, em 1926, no final da República, era não só iletrado mas analfabeto) ou de produção literária e enciclopédica para o povo, Ferro sabe bem que esse desafio está a ser e será ganho por aqueles, que dos Cadernos da Seara Nova, aos de 
Agostinho da Silva ou aos da Livraria Inquérito (de Eduardo Salgueiro) à Biblioteca Cosmos, de Bento de Jesus Caraça, se perfilam à Esquerda, quer seja democrática, republicana, anarquista ou comunista, contra o Estado Novo e a sua liminar política de negação da liberdade, das livres letras e das artes livres.

Não há pois registos significativos de literatos ou escolas literárias nascidos no interior do regime, no "suave" fascismo prático sem fascistas teóricos que em Portugal se instala: nem é preciso um intelectual inscrever-se no Partido único ("antipartidos") para se ser escritor reconhecido e, exceptuando figuras relativamente menores da geração que se segue e sobra do finissecular nacionalismo neo-romântico e do lirismo conservador patrioteiro (António Correia de Oliveira, Augusto de Castro, por exemplo) ou do "lusitanismo" (Afonso Lopes Vieira), nenhum dos já consagrados ou dos que se viriam a consagrar, neste período, na República das Letras, figura nas listas da SPN, o órgão promotor e mediador da visão elitista da cultura oficial para consumo das massas, ou precisa sequer do regime e suas encomendas oficiais para coisa alguma, senão para se lhes opor.

Em breve, fóruns alternativos, à volta de revistas e correlativas áreas literárias, críticas e de ideias, como Seara Nova (1921-), presença (1927-1940), Vértice (1942-), criam num campo incontrolado, mesmo se censurado e perseguido, a mais fecunda produção literária (CARVALHO, 2011-2012). É a época em que, passada a adulação do velho simbolismo do fim de século (António Nobre, Eugénio de Castro, Camilo Pessanha) e do academismo (Júlio Dantas), agora são reconhecidos Raúl Brandão, Teixeira de Pascoais, Aquilino Ribeiro, Afonso Duarte, como os vates do espírito, da língua, da terra; e que Ferreira de Castro, após os Emigrantes (1928) e a sua fascinante experiência narrada pelo imenso Brasil, iniciara já a obra ímpar e tão injustamente mal evocada. É a época da afirmação poética e novelística de Miguel Torga, numa literatura da consciência de si que não abstrai da consciência das condições, políticas, sociais, intelectuais, em que ela mesma não pode medrar sem se insurgir; da expatriação de Rodrigues Miguéis, pela fascinação crítica da grande metrópole norte-americana; da gestação do neo-realismo do Novo Cancioneiro, firmado em Coimbra. É a época, enfim, da poesia inquietante e nova de José Régio, uma voz própria na cauda e no caudal do cometa Fernando Pessoa que incendiara os céus, cujo rasto é ainda, e apenas para alguns, pouco perceptível.

Tudo isto evidencia empiricamente o estado de debilidade endémica do próprio problema de investigar uma hipotética literatura salazarista em pleno salazarismo, o que 
não deixa de ser estranho. Há, com efeito, um pelotão quase inominável de uma literatura conservadora (encimado na versão urbana e cosmopolita por Joaquim Paço d' Arcos) que endeusa valores da terra e o regionalismo, que faz o apólogo da religião tradicional e do Império (Guedes de Amorim, Tomás de Figueiredo), seguindo o trilho mítico da "acção evangelizadora dos portugueses no mundo", que louva a honradez moralizante de pobres e excluídos, que se dedica a estudos moralizantes e históricos, dos quais $D$. Luísa de Gusmão, de Hipólito Raposo, é o paradigma tardio (1947). Porém, em rigor, nada disso é próprio do salazarismo, diga-se, nada disso é fruto de uma invenção ideológica do ditador ou dos seus comissários.

Trata-se antes de um arrastamento, reaproveitamento do legado tradicionalista e conservador, do historicismo ou até das modalidades do pietismo literário (do converso Manuel Ribeiro, por exemplo, ex-anarcossindicalista) que desde o ocaso do século XIX e do tremor do Ultimatum (1890), não estava sepultado e se reafirmará quando o fervor e a fé cívica anticlerical, a literatura naturalista e de "patologia social" (de que Abel Botelho, com $O$ Barão de Lavos, fora o caso maior), entrar em forçado eclipse, com a queda da República às mãos dos militares. Quer dizer, o regime não criou, per si, cânones específicos e mecanismos do gosto, normativizando antes as narrativas ficcionais "portuguesas" e congelando uma iconologia narrativa, sub specie (Herculano, Garrett, Eça de Queirós, Camilo Castelo Branco), ao contrário do que ocorrerá em novas linguagens e estéticas do cinema, da radiodifusão ou, nas disciplinas antigas, com a portugalização do gosto pictórico, o pitoresco paroquial, ou com a monumentalidade fascizante na arquitectura oficial, o grotesco imperial.

Além doutros factores, perguntar-se-á se terá subsistido e será reconhecido, no campo específico da estética literária, um verdadeiro livro de estilo do Estado Novo, à semelhança daquele, "pedagógico" (tratava-se de facto da imposição de uma didactologia), que norteava a sua política educativa, mormente no ensino básico, onde as Lições de Salazar impunham o ideal estético-moral da pobreza limpa, da redenção espiritual, o culto submisso aos chefes e hierarquicamente ao ditador, o mais modesto e perfeito. Porém, só esta axiologia traria o ex novo ao discurso literário; e ela encontra mediações criativas de fraca intensidade, impugnando estéticas da recepção eficazes e galvanizadoras. Enquanto estética literária, baldadas tentativas frouxas de reler o Modernismo como mero discurso propagandístico do poder, aquele escapou à canonização política. Não há, de primeira plana, Marinettis nem Pound’s no palco literário da luta política e, ademais, a vertigem da velocidade e a panegírica da 
modernidade reaccionária desencadeiam antídotos e resistências no imaginário fixista e ruralista, recíproco do tom épico da epopeia, com o qual se pintam em cores delidas o viver habitualmente (CARVALHO, 2003: 135 e ss).

Verificada a impossibilidade da declaração criativa de uma política cultural, a célebre política do espírito enunciada por António Ferro em 1933 redundou, no campo literário, num serviço sistemático de censura cada vez mais especializada, objectivando uma prática negativa sobre as condições subjectivas e objectivas da produção. Assim, ela reflectiu-se, no plano criativo e da literatura das ideias, na política sobre o espírito e, em particular, na sua longa negação: na proibição dos estrangeirismos e na interdição de edições, autores e leituras, num larvar e primário discurso anticomunista, antiliberal, antidemocrático, na vigilância moralista dos "bons" usos e costumes, mormente em narrativas de conteúdos explícita ou implicitamente sexuais ou "imorais", relevando do desprezo contínuo à Modernidade gnoseológica correlato do ódio visceral ao pensamento livre e suas mediações artísticas.

A política do espírito, como todas as políticas impositivas e planificadoras, cifrouse numa polícia do espírito. A imediação fonética e semântica assinala estoutro equívoco maior-querer governar os espíritos, escrevera-o J.-M. Guyau no declinar do século XIX, é mil vezes pior do que querer governar os corpos.

\section{Equívoco maior: a cristianização da Mensagem}

No reverso, o segundo grande equívoco do projecto nacionalizador do Estado Novo cifrar-se-ia, mais tarde, num logro. Tratava-se de legitimar à sombra do nacionalismo cristão um poeta ignorado; e de galardoar, na perspectiva e em proveito do regime, o grande poema que no período considerado, de facto, se publicará em Portugal. À sagaz oportunidade de António Ferro se deve a iniciativa de repescar o seu amigo e antigo patrão (de Orpheu) para o Concurso de Poesia “Antero de Quental” (1934), da SPN. Os contornos do caso são por demais conhecidos, pelo que nos limitaremos a retomar uma hermenêutica interna (CARVALHO, 2011) desse enorme equívoco.

Veja-se. Como ars historiae, o poeta lê no próprio texto clássico e épico feito em "versos de almas tranquilas". Mas nada tranquila foi a sua recepção entre os poucos que o liam e admiravam. Casais Monteiro, logo lamenta a estreita medida nacionalista do livro inaugural em português; mas a resposta desconcertante desautoriza o jovem 
admirador, numa epístola bem conhecida: "concordo com os factos que foi a melhor estreia que poderia fazer", "sou um dos poucos poetas portugueses que não decretou a sua própria infalibilidade, nem toma qualquer crítica, que se lhe faça, como um acto de lesa-divindade".

Em Mensagem deu-se, década e meia, o poeta à tarefa de sintetizar a obsessão pelo inacabamento, a posteridade, a (sua) imortalidade, que não é a da Camoniana narrativa mítica do achamento mas a do superCamões, no mesmo mar interior e anterior, Ó mar anterior a nós, o da ilha indescoberta de "A última nau", o do porto sempre por achar. Foi a melhor, a mais completa, estreia em poesia portuguesa que poderia fazer. Tudo hesitou; no demais sobrepujam formas dubitativas às definitivas; a Caeiro, teve de matá-lo, e a Reis, teve de emigrá-lo, para o Brasil; Campos, foi um flagelo para publicar a não ser fragmentos, embora imortais; do Banqueiro anarquista, Pessoa não conseguiu ultimar a edição definitiva. Nem o Livro de Bernardo Soares, nem a "novela policiária", estavam completos quando o tradutor de correspondência estrangeira (Venham dizer-me que não há poesia (.) nos escritórios, escreve na Ode Marítima), entrou no hospital de S. Luís dos Franceses, para morrer.

Se a sua arte poética é Tratado de precisão teórica e técnica, sobretudo o seu ethos fica nela salvaguardado através da criação mitopeica, mitopoética, a experiência de perfuração da opacidade do tempo: na antropomorfização da Europa, de Portugal, do Mostrengo, da mão do Ocidente, antemanhã do passado, nevoeiro e incerteza, dá corpo à ilusão consciente; na reminiscência platónica que é conhecer; na invocação explícita dos pais da pátria e, neles, a Afonso Henriques, Pai, foste cavaleiro, a espada que na visão homológica da história passa de mão em mão pelas gerações é a mesma, pode ser o Graal ou a espada de Aquiles; as mães, Tareja, Filipa de Lencastre, cujos seios nutriram Portugal, o envelhecido homem que foi o teu menino, amamentaram também a loucura sem a qual a besta sadia, é cadáver adiado que procria; a esfinge sem rosto de Ulisses, o puro começo mítico do mundo, e a estranha dança da fogueira dos Titãs delindo-se em silêncio pelos vales da Terra, certificam o tempo e o território épicos onde a Teogonia, como em Hesíodo, desagua na mitogonia e se desfaz, antropogónica, como onda quebrada, revelando a orla que a espuma oculta.

Deuses, ou o Deus da invocação, são figurações platónicas arrancadas à prospecção do nada que o voluntarismo mosaico propusera. O poeta conjuga no "nacionalismo místico" a sua religiosidade herética: para o militante simpótico, não são mortos ou imortais os que no simpósio dos deuses estão a mais, mas vivos que não 
alcançam ou entendem o signo imortal da existência singular. Pessoa não é o Capitão do Fim no poema mas esse que regressarei: as dismorfias da Esperança (Sperai, 'Sperança consumada, esp'rança), como se nem a palavra se objectivasse inteira, a aventura e a obra, são vozes que vêm no ressoar das ondas, conferindo-lhes a densidade trágica do imperceptível, no instante em que se anunciam; acaso e destino, Tempo e Loucura, jogam-se como dados momentâneos num tabuleiro cósmico da História; a circularidade de um tempo quasi-perfeito é o estásimo onde a cada instante estilhaçado (É a Hora!; Não sei a hora, mas sei que há a hora) se intrometem imagens refractadas do futuro, do passado, do presente - já anunciado por Campos na Ode Triunfal, "Porque o presente é todo o passado e todo o futuro", e noutros versos e assinaturas em livros velhos que arquivam,

\section{Ó enigma visível do tempo, o nada vivo em que estamos!}

-, presente mediador no qual É a Magia que evoca / o Longe e fez dele história, num vaivém angustiante de marés e de marinheiros que na galeria estática dos retratos do tempo faz ressurgir luzes de fantasmas de velas, ventos e navios, entre o passado mnésico e a aurora espectral, o despertar do sol por nascer, primavera adiada em cada vida, cada época, cada civilização, senão a primeva que se imaginou civilizada.

O círculo indefinido da metapoética enlaça as palavras: o mundo e a sua temporalidade cabem inteiros em oito versos do poema. Na cosmogonia pessoana, se o “mundo é um pensamento" como lera Oliveira Martins em Camões, o poeta demiurgo, o que usa o poder de expressão, mediador, reinstala-se no espaço clássico ora vazio - um vazio presente se não for inteirado por miragens reconstrutivas do passado e ilusões prospectivas do futuro -, entre o Caos e o Cosmos, homens e deuses, o indecifrado e o que se pensa saber. O poeta é aquele que reconhece nesse cosmo tanto a criação humana, sonho, não só repetido referente de Mensagem mas da obra estilhaçada (também o sonho assume o carácter apocalíptico n' Os Lusíadas), quanto movimento regulado por forças e leis que tenta achar. Os que lêem no poema a numerologia da nova Bíblia, reduzindo-o a prece escatológica ou a tabuada de três simples, apenas fartam a sua mesma sede dogmática de leitores. Espelho de sublimes distorções, Mensagem é a arte como história que acha o acabamento, faz-se história, reatando em Camões o paganismo transfigurador do cristianismo. 
Relendo-o àquela luz religa duas tendências, a hermética e neopagã, em que dividiu a alma. Afinal, é possível o encontro heterodoxo, esotérico e hermético, de matriz rosacruciana, afligido de crescente intensidade - mas o construtor de Poiesis não faz "votos perpétuos" num Deus-pessoa, ou em homens-deuses, como testemunhou Caeiro, o gentio de uma religião universal que só os homens não têm: pois Pensar em Deus é desobedecer a Deus.

Ora, se a reabilitação gnóstica e mística da tradição judaica e neoplatónica inscreve as Idades do ser nas Idades do mundo, a degeneração é vivida na esperança do retorno à Idade do Ouro, mas também instaura, em contradição radical, uma epistemologia poética, não se acha outra expressão para designar essa tensão para inscrever um novo método de conhecer os limites temporais através da poesia, para sair fora do tempo - e caminho para decifrar não o real em si mas as significações que dele se podem eleger, num jogo que fura os limites do tempo e o nexo das Eras numa reversão retórica da temporalidade. Paganizando Espinosa, para o poeta que lhe herdou o carácter refractário e insurrecto e, talvez, o pampsiquismo que Pascoais esquecia, só sob o ponto de vista dos deuses a história seria inteligível: e como a visão sub specie aeternitatis parece vedada a mortais, pela intervenção dogmática do arame farpado autoritário, entra em incumprimento a presunção omniexplicativa dos incautos: pode resguardar-se Pessoa do divã analítico vazio do Ser, ou não ser mais usado o cadáver ahistórico para lhe dissecar a alma e a vida.

$\mathrm{Na}$ Mensagem fundem-se ciclos históricos e os tempos ou Idades do ser (o quinto império é o do triunfo da Poesia, como a História do futuro o fora da Prosa, para António Vieira, o escritor que viveu no meio do Atlântico) na "Raça" dos descobridores, mítica raça forjada pelos aedos gregos, pois, se deuses e homens são uma raça só, como queria Píndaro-Pessoa, o poeta argonauta dos novos tempos aditaria o desprezo por tudo, di-lo em “Ultimatum”, o que seja menos que descobrir um mundo novo: o poema é a descrição fantasiosa e a dilaceração desse novo mundo metahistórico e a notícia do achamento gnóstico da incerta hora em que o intuiu.

Qualquer referência histórica é contrafacção historiográfica: a poesia triunfa sobre a história, como evento e género literário. A invenção é a arma de arremesso, mitopeia da órfica descida aos infernos para resgatar das trevas o que resta da divina imperfeição humana trazendo à tona, do fogo a libertando, a elegia humana da divina imperfeição. A falha grosseira de actuais e velhas leituras historicistas de Mensagem, que ao sobrevalorizarem a "história" e o "destino nacional" ignoram a historicidade do 
poema, reside nesse preciso desprezo pela dimensão narrativa da poética como gnose, inventiva capacidade mitopeica. Apesar da claridade redentora, Mensagem não nos salva de nós próprios: não é promessa de regime, programa de governo, ou receita orçamentada na insciente política da cegueira.

Ora, foi este equívoco voluntário e intencional, que o Estado Novo na política do espírito propagandeou durante décadas e cultivou nas escolas, tal como eu aprendi na meninice: mas o poema não é o guião da velha catequese autoritária, mas o diário extraordinário de um achamento do espírito, ao qual só uma Philosophia libera poderá aceder.

Entenda-se doutro modo, sob o ponto de vista hermenêutico, que o nacionalismo representou, para Pessoa, uma outra face para apreender o ecumenismo profético que a sua escrita arrasta e o universalismo, situado e descentrado, que a sua Poesia exige. Ao invés, para o regime que paradoxalmente adoptou a Mensagem como cânone, em busca de raízes mitológicas para a sua própria afirmação política e de pré-textos fundamentadores da sua sobrevivência ideológica, o nacionalismo não era mais, como vulgarmente hoje ainda o é - neste tempo de ressurgimentos nacionalistas e de outras aberrações do fundamentalismo localista, do que um pré-herderiano modo de entender a complexidade do mundo e de minorar e reduzir, por via do "realismo" tomista, a quasi infinita multiplicidade do cosmos a uma fórmula de compreensão de escala reduzida e redutora.

\section{Referências Bibliográficas}

CARVALHO, Paulo Archer de (1994). Memória mítica da Nação. O caso do Integralismo Lusitano, Vértice, II Série, 61, Julho-Agosto, pp. 51-66. (2003). Da Nação Portuguesa (1914-1938) ao Integralismo Lusitano (1932-1934): a insurreição dos intelectuais. ASTRO, Zília Osório de(cord.), Revistas, Ideias e Doutrinas. Leituras do Pensamento Contemporâneo, Lisboa, Livros Horizonte, pp. 135-153.

. (2011). Mitopeia. Notações para uma poiética do tempo e da história nos estilhaços da antropodiceia pessoana, Revista de História das Ideias, 32, FL-Universidade de Coimbra, pp. 359-393. (2012[2011]). Três notas sobre a Modernidade da Seara Nova (1920-1930), Seara Nova, número evocativo, 1718, Inverno de 2011.

\& Catroga, Fernando (1996). Sociedade e Cultura Portuguesas (II), Lisboa, Universidade Aberta, Colecção Universitária, 1996. 
Artigo recebido em 10 de outubro de 2016.

Aprovado em 26 de novembro de 2016.

DOI: 10.12957/intellectus.2016.26665 